\title{
Improving collaboration in construction projects in developing countries: the case of Kurdistan region of Iraq
}

\author{
Hazhar Faris ${ }^{1}$ David Hutchinson ${ }^{2}$ and Mark Gaterell ${ }^{3}$
}

\begin{abstract}
The construction sector is criticised for being fragmented and for having a large number of problems between stakeholders such as adversarial relationships, lack of trust and ineffective communication. These issues emerge especially in developing countries. Collaboration has been introduced as a solution to such issues. However, delivering an effective process of collaboration is a challenge with a wide range of factors involved. This paper identifies and sorts the critical factors that affect collaboration in the construction sector and recommends ways to adapt such factors in the sector. Through a comprehensive review of the literature, two groups of critical success factors have been identified to improve such practices, hard factors and soft factors. This study contributes to the scarce literature about collaboration in the construction industry in the Kurdistan, and identifies factors of collaboration that construction projects need to adopt in order to improve their performance.
\end{abstract}

Keywords: Collaboration, critical factors, construction, developing countries, Kurdistan-Iraq.

\section{Introduction}

Adversarial relationships and a lack of collaboration are familiar challenges in the construction industry. Many researchers have insisted the construction industry needs to improve collaboration between involved stakeholders to enhance the performance of projects (Grilo, Zutshi, Jardim-Goncalves, \& Steiger-Garcao, 2013; Morrell, 2015; Shelbourn, Bouchlaghem, Anumba, \& Carrillo, 2007). The construction industry has seen three different delivery approaches: traditional construction management (TCM), project management (PM) and partnering. In the traditional approach, parties compete to win bids and relationships are defined based on strict contracts. TCM has resulted in many adversarial relationships in the construction sector. The PM model was developed to overcome challenges facing construction projects; however, it also faced many difficulties in the industry. Then, partnering was introduced to the construction sector by Latham (1994) and aimed at solving the problem of fragmentation of the sector. Partnering improved project delivery methods, however, relationships are far from collaborative and the construction sector still needs to take serious actions to solve this problem.

Although construction projects face many challenges globally, these obstacles are increased in the case of developing countries (Ofori, 2000). Since, these countries have more severe social, cultural and economic situations (Elkhalifa, 2016). Similarly, in the Kurdistan region of Iraq construction projects are confronted with a wide range of problems such as a clear lack of collaboration between involved parties (RTI International, 2008). This article aims to address this issue by identifying the critical factors needed to improve collaboration in construction projects in developing countries and especially in Iraqi Kurdistan.

School of Civil Engineering and Surveying, University of Portsmouth, Portland Building, Portland Street, Portsmouth, PO1 3AH, United Kingdom,

Email: hazhar.faris@port.ac.uk

Faculty of Technology, University of Portsmouth, United Kingdom.

School of Civil Engineering and Surveying, University of Portsmouth, United Kingdom. 


\section{Literature review}

Globally, the construction industry is a main contributor to economic growth and to development of nations, this contribution increases in the case of developing countries (Giang \& Pheng, 2011; Ofori, 2007). Lopes, Ruddock, and Ribeiro (2002) investigated the role of construction in developing countries and argued that there is a significant relationship between the amount of construction going on and economic growth for countries still at the developing stage. In Iraqi Kurdistan, despite the construction sector being essential to the growth of the region, construction faces many obstacles such as organizational issues, adversarial relationships and a clear lack of collaboration (Mustafa, 2017). Shawkat, Al-Din, and Kuzović (2018) agreed that several barriers are confronting construction industry in the Kurdistan region including deficiencies in the construction process, considerable shortage of skilled professionals, socio-cultural, technical and management factors. According to Zebari and Ibrahim (2016), the construction process in the Kurdistan is highly uncommunicative, and involved stakeholders are not collaborating, this lack of interaction between participants has resulted in underperformance of industry products. The authors added that there is a clear lack of collaboration between construction and design teams.

Additionally, the sector is growing for many reasons such as the growth in foreign investment in the region as illustrated by the World Bank (2015). Actually, Barnard (2013) expected more developments and progress in the Kurdistan region. Consequently, the need for improving relationships and collaboration between the stakeholders involved in the project lifecycle is increasing. Researchers have agreed that collaboration is important for improving construction practices and that it has many benefits for the industry (Kożuch \& SienkiewiczMałyjurek, 2016; Meng, 2013; Shelbourn et al., 2007). Despite its benefits, delivering effective collaboration in the construction industry is still a challenge, a range of factors need to be considered as a means for achieving collaborative environments (Koraltan \& Dikbas, 2002; Shelbourn et al., 2007). Therefore, this research reviews the literature to identify the most critical factors needed to deliver effective collaboration.

\section{Research methodology}

A considerable amount of literature exists on the factors to deliver collaboration and ensuring better relationships within construction projects. In this research, a comprehensive review has been undertaken to identify critical success factors of collaboration. The process of identifying factors of collaboration, partnering and alliancing from the previous literature has been used by other researchers such as (Chan, Chan, \& Ho, 2003; Nyström, 2005; Yeung, Chan, \& Chan, 2007). The authors have reviewed the most relevant literature from 2000 to 2018. To identify a sample of papers to be reviewed, the first step was to search for keywords in titles and abstracts of the articles. As the past literature has used different words to describe collaborative relationships, such as partnering, strategic partnering, alliancing, teamwork, collaboration and so on. Similarly, studies describing factors of collaboration have used different terms such as critical factors, attributes, attitudes, components and so on. In this research, a combination of words from both aspects of collaboration and factors has been used to identify related studies. Then, related articles were scanned qualitatively to identify most-closely related studies. Similar approaches were also used by Kożuch and Sienkiewicz-Małyjurek (2016) and Wu, Greenwood, and Steel (2008) in collaboration research. This process resulted in 35 articles being considered for this research which are listed in Table 1.

The most commonly mentioned factors in the articles were identified. Later, to determine whether similar factors are needed in the Kurdistan region, those factors were compared to the literature of Kurdistan construction and similar challenges were found (Abramzon et al., 2016; 
Mustafa, 2017; RTI International, 2008; Shawkat et al., 2018; Zebari \& Ibrahim, 2016). Additionally, some factors were merged into one item, and the greater group were kept. For example, the literature has linked the early involvement of participants and contracts and sometimes has used them for the same purpose. The early involvement of participants depends on the type of contract, as explained by Hughes, Williams, and Ren (2012). Since early involvements have been mentioned more frequently than contracts; that former factor has been kept. The final factors identified from the literature are shown in Table 2 with their definition outlined below.

\section{Critical factors of collaboration}

\section{Trust}

For collaboration to be effective, parties need to build trust (Meng, 2013). This is because if the level of trust is low, parties tend to act against each other and it is not possible to work collaboratively. Construction organisations need to improve the level of trust between their practitioners by using new ways of working (Wu et al., 2008). It very important in construction projects that stakeholders take time out from routine activities to increase the level of social interaction in order to build mutual trust and respect (Shelbourn et al., 2007).

\section{Communication}

Construction organisations need effective communication skills to exchange visions and ideas and to reduce misunderstandings and produce effective working environments (Cheng, $\mathrm{Li}, \&$ Love, 2000). Clear communication channels create formal and informal ways to exchange information, increase shared awareness and obtain shared benefit (Patel, Pettitt, \& Wilson, 2012). To attain a steady process, design and construction teams need to have clear communication channels to increase shared awareness and avoid technical issues.

\section{Mutual goals}

Establishing mutual goals is a major contributor to the success of projects and is regarded as a prerequisite of success for collaboration (Bresnen \& Marshall, 2000a). Construction teams need to agree on mutual goals at the highest levels of management and transfer those goals to the lower levels to ensure all involved parties work toward a common target.

\section{Conflict resolution}

Disputes are present in all construction projects depending on size, duration and complexity of contracts. However, Xue, Shen, and Ren (2010) indicated that a proper strategy of conflict resolution provides stability and prevents many issues related to adversarial relationships in traditional contracting approaches. Practitioners need to solve disputes at the lowest level possible before rapid escalation to legal authorities (Bayramoglu, 2001). If a conflict reaches a point that requires a court to solve it, it may cause all parties to lose time and incur a cost.

\section{Top management support}

Nyström (2005) identified top management support as the main prerequisite for developing a collaborative approach in the construction industry. Therefore, in order to achieve targets set for parties working at different levels in construction projects, top management needs to show full support. Support from management is essential to develop and maintain relationships at a high level and to avoid disputes (Dikmen, Birgonul, Ozorhon, \& Eren, 2008). 
Table 1. Reviewed papers to identify factors of collaboration

\begin{tabular}{|c|c|c|c|c|c|c|c|c|}
\hline Ref. no & Author(s) & Year & Ref. no & Authors & Year & Ref. no & Author(s) & Year \\
\hline 1 & Akintoye et al. & 2000 & 13 & Lu and Yan & 2007 & 25 & Patel et al. & 2012 \\
\hline 2 & Black et al. & 2000 & 14 & Shelbourn et al. & 2007 & 26 & Akintan and Morledge & 2013 \\
\hline 3 & $\begin{array}{l}\text { Bresnen and } \\
\text { Marshall }\end{array}$ & 2000 & 15 & Yeung et al. & 2007 & 27 & Meng & 2013 \\
\hline 4 & $\begin{array}{l}\text { Bresnen and } \\
\text { Marshall }\end{array}$ & $2000 \mathrm{~b}$ & 16 & Dikmen et al. & 2008 & 28 & Rahman et al. & 2014 \\
\hline 5 & Cheng et al. & 2000 & 17 & Erdogan et al. & 2008 & 29 & Azhar et al. & 2014 \\
\hline 6 & Bayramoglu & 2001 & 18 & Koutsikouri et al. & 2008 & 30 & Gassel et al. & 2014 \\
\hline 7 & Cheng and $\mathrm{Li}$ & 2001 & 19 & Wu et al. & 2008 & 31 & Bidabadi et al. & 2015 \\
\hline 8 & Cheng and $\mathrm{Li}$ & 2002 & 20 & Eriksson & 2010 & 32 & Bidabadi et al. & 2016 \\
\hline 9 & $\begin{array}{l}\text { Koraltan and } \\
\text { Dikbas }\end{array}$ & 2002 & 21 & Xue et al. & 2010 & 33 & $\begin{array}{l}\text { Kozuch and } \\
\text { Sienkiewicz-Małyjurek }\end{array}$ & 2016 \\
\hline 10 & Chan et al. & 2004 & 22 & Bemelmans et al. & 2012 & 34 & Koolwijk et al. & 2018 \\
\hline 11 & Vaaland & 2004 & 23 & Hughes et al. & 2012 & 35 & Nursin et al. & 2018 \\
\hline 12 & Nystrom & 2005 & 24 & Meng & 2012 & & & \\
\hline
\end{tabular}


Table 2. Factors of collaboration and references mentioned

\begin{tabular}{|c|c|c|c|}
\hline Rank & $\begin{array}{l}\text { Critical } \\
\text { Factors }\end{array}$ & Frequency & $\begin{array}{l}\text { No. of papers (from table1) mentioned the } \\
\text { factor }\end{array}$ \\
\hline 1 & Trust & 31 & $\begin{array}{l}([1],[2],[3],[4],[5],[6],[7],[8],[9],[10],[12],[13], \\
{[14],[15],[16],[17],[18],[19],[21],[22],[23],[24],} \\
[25],[26],[27],[28],[29],[31],[33],[34],[35])\end{array}$ \\
\hline 2 & $\begin{array}{l}\text { Communica- } \\
\text { tion }\end{array}$ & 26 & $\begin{array}{l}([2],[4],[5],[6],[7],[8],[9],[10],[14],[15],[16],[18] \\
,[19],[21],[22],[23],[24],[25],[27],[28],[30],[31], \\
[32],[33],[34],[35])\end{array}$ \\
\hline 3 & $\begin{array}{l}\text { Conflict } \\
\text { resolution }\end{array}$ & 21 & $\begin{array}{l}([5],[6],[7],[8],[9],[10],[11],[12],[13],[15],[16], \\
[17],[19],[21],[23],[24],[25],[27],[28],[29],[35])\end{array}$ \\
\hline 3 & Mutual goals & 20 & $\begin{array}{l}([1],[4],[5],[9],[10],[12],[13],[14],[15],[18],[19], \\
[21],[22],[23],[24],[25],[27],[28],[29],[33])\end{array}$ \\
\hline 5 & $\begin{array}{l}\text { Top } \\
\text { management } \\
\text { support }\end{array}$ & 20 & $\begin{array}{l}([1],[2],[5],[7],[8],[10],[12],[13],[15],[16],[20], \\
[19],[21],[22],[25],[28],[29],[31],[32],[34])\end{array}$ \\
\hline 6 & Commitment & 19 & $\begin{array}{l}([1],[2],[3],[5],[7],[8],[10],[13],[14],[15],[16], \\
[19],[22],[25],[28],[31],[32],[33],[34])\end{array}$ \\
\hline 6 & $\begin{array}{l}\text { Gain-pain } \\
\text { sharing }\end{array}$ & 18 & $\begin{array}{l}([1],[2],[3],[6],[9],[13],[14],[15],[19],[20],[21], \\
[22],[23],[24],[27],[28],[29],[34])\end{array}$ \\
\hline 8 & Culture & 16 & $\begin{array}{l}([1],[2],[4],[5],[9],[13],[14],[16],[18],[21],[22], \\
[25],[29],[31],[33],[35])\end{array}$ \\
\hline 9 & $\begin{array}{l}\text { Resource } \\
\text { sharing }\end{array}$ & 14 & $\begin{array}{l}([5],[7],[8],[10],[12],[13],[14],[15],[17],[19],[25] \\
,[26],[28],[33])\end{array}$ \\
\hline 10 & $\begin{array}{l}\text { Early } \\
\text { involvement }\end{array}$ & 14 & $\begin{array}{l}([4],[5],[6],[10],[12],[14],[15],[20],[21],[23],[25] \\
,[29],[31],[34])\end{array}$ \\
\hline 11 & Clear roles & 13 & $\begin{array}{l}([2[,[4],[10],[14],[16],[18],[23],[25],[27],[28], \\
[31],[32],[33])\end{array}$ \\
\hline
\end{tabular}

\section{Commitment}

A core item required for the success of collaboration is commitment by the involved parties; commitment and motivation are required to reinforce relationships in construction projects (Bresnen \& Marshall, 2000b). Success of collaboration in construction projects is highly influenced by the commitment of parties in providing shared resources and working toward common objectives.

\section{Gain-pain sharing}

Another crucial factor for a collaboration to succeed is a gain-pain sharing system between parties. It can be argued that the absence of a proper means of gain-pain sharing is responsible for restraining resources and information, which results in a lack of collaboration. The importance of risk sharing increases in the case of larger projects. As explained by Lu and Yan 
(2007), in complex projects with a high degree of uncertainty it is essential to share risks and rewards in a systematic way to gain effective collaboration.

\section{Culture}

Project and organisational management trends are moving toward more decentralised, flexible and collaborative organisations. However, the success of this step toward collaboration is associated with understanding the crucial role of cultural changes within this process (Black, Akintoye, \& Fitzgerald, 2000). Culture could indicate methods of communication and engagement of the members in projects.

\section{Resource sharing}

Resource sharing increases trust and respect between parties and helps to produce collaborative environments. Sharing resources increases the willingness to work collaboratively and facilitates the development of relationships in an efficient way (Rahman, Endut, Faisol, \& Paydar, 2014).

\section{Early involvement of key participants}

Traditional ways of project delivery have restricted involvement of some key participants at early stages. These approaches have resulted in adversarial relationships and underperformance in construction projects. The early involvement of participants increases the level of understanding, thus reducing disputes and improving team performance. Collaborative teams need to be built on the early involvement of key members so as to move away from a conservative construction culture and improve the performance of industry products (Hughes et al., 2012).

\section{Clear Roles}

For a collaboration to be successful, roles need to be clearly defined and individual responsibilities need to be coordinated toward achieving the project target (Patel et al., 2012). The complexity that exists in construction projects makes it difficult to clarify the responsibilities of each individual. However, Black et al. (2000) indicated that a clear understanding of responsibilities is required if collaborative working is to succeed, and that this requires the effort of all project stakeholders.

\section{Discussion}

\section{Analysis of the study results}

After reviewing the literature, 11 critical factors were identified and explained. In order to clarify the confusion that exists in the literature about collaboration factors, these factors are classified into two categories: hard factors and soft factors. Where, hard factors are tangible items and tools that mainly depend on contractual agreements (Yeung et al., 2007). While, soft factors are items that depend on the behaviour of participants and organisations' personnel (Shelbourn et al., 2007). Those soft factors need to be developed throughout the lifecycle of a project. Soft factors identified in the literature include trust, communication, mutual goals, and culture. These factors are necessary for any kind of project to increase interaction and understanding between parties. Focusing on soft issues is necessary to achieve effective collaboration. However, soft factors alone are not sufficient to deliver a successful process of collaboration; hard factors and systems need to be in place to complete the process. Hard factors determined in this study include conflict resolution systems, top management support, gainpain sharing systems, resource sharing, clear roles, and the early involvement of key 
participants. Figure 1 indicates the most critical factors grouped into hard and soft factors of collaboration.

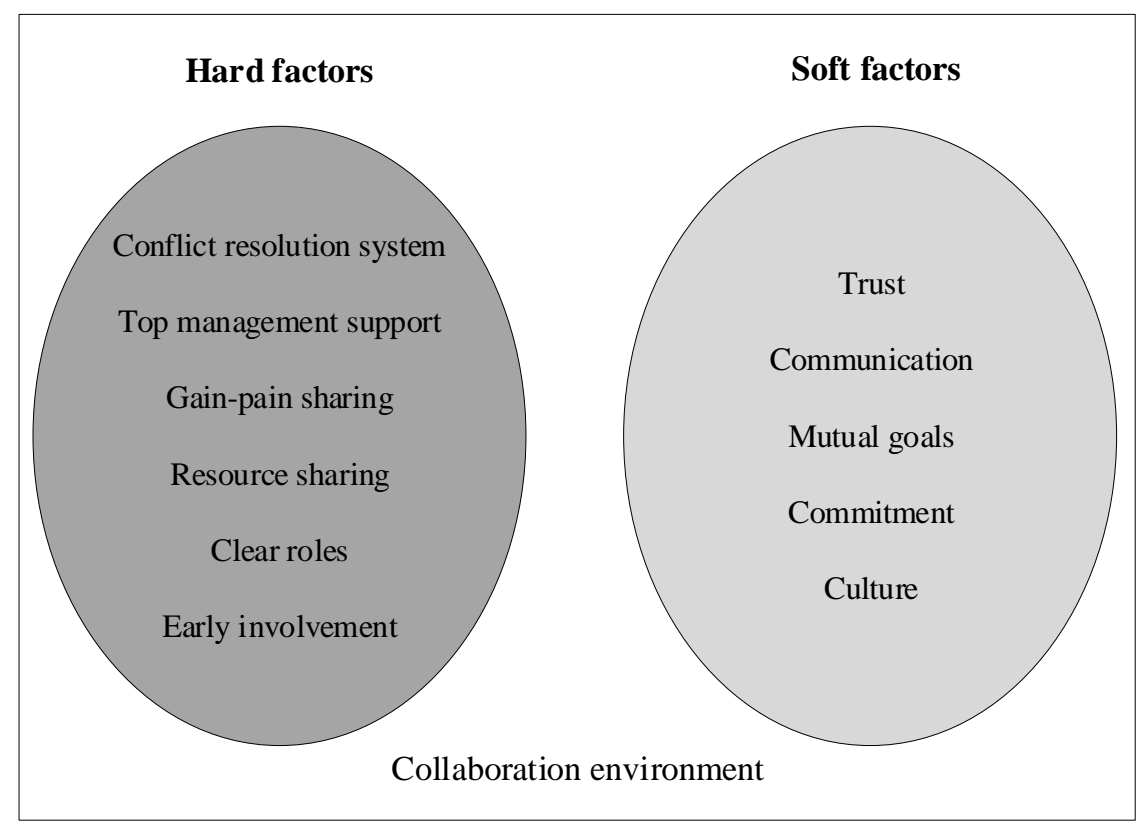

Figure 1. Two groups of collaboration factors

Nyström (2005) classified factors of partnering into general prerequisites and components. Prerequisites are factors that need to be provided before the formation of a collaboration process while components are factors established and developed during the process of collaboration. Looking at the factors found in this research, prerequisites for a collaboration process are top management support, early involvement of key participants and resource sharing. These factors are necessary to establish a collaborative working environment between construction parties, without providing prerequisites it is not possible to build a collaborative environment. Other factors identified in this research can be described as items to be developed during the collaboration working process which are trust, communication, mutual goals, conflict resolution, commitment, gain-pain sharing, culture and clear roles.

The findings of this research are consistent with those of (Chan et al., 2004; Cheng \& Li, 2001), both of whom looked at critical success factors for partnering in the construction industry. Compared to those studies, it can be noted that the role of both trust and communication factors has increased. Obviously, the importance of communication has increased with the implementation of complex designs and the use of advanced technologies in construction projects. To simplify complex designs and to enable effective collaboration clear communication channels need to be established (Koutsikouri, Austin, \& Dainty, 2008). Similarly, the importance of trust has increased, in this research mutual trust was identified as the most critical factor. Other factors found in the literature included the evaluation of the process, contract types, technology, sharing information, respect and experience.

\section{The implications for construction projects in the Kurdistan region and further study}

The construction sector in Iraqi Kurdistan consists of public and private sectors. Implementing collaboration in the public sector could face more challenges than the private sector. In the public sector, government rules place many policies that do not encourage collaboration such as awarding contracts based on lowest-bid basis and restrictions on early involvement of 
contractors. Construction is a conservative sector with a wide range of adversarial relationships. In order to implement collaborative approaches governments need to enforce new rules, for example, at bid awarding stage they could restrict cost considerations to focus on lifecycle cost rather than lowest-bid. To enable collaboration in a conservative construction sector, Koraltan and Dikbas (2002) recommended to award contracts on the most economically advantageous offer instead of the lowest initial bid. Since, in many cases, the lowest initial bids are not the most advantageous option if lifecycle cost is considered. Collaboration has many benefits regarding cost reduction.

Implementing collaborative approaches in the public sector obliges construction organisations to work under, and get used to, the new approaches. This change can make organisations realise the benefits of collaboration and increase interest in adopting new approaches in the private sector. The Kurdistan Regional Government (KRG) could help in improving collaboration and in using public funds efficiently by assessing bids based on other criteria rather than just lowest-bid and bringing in contractors at an early stage (Muhammed, 2015). Additionally, in the Kurdistan region, there are a significant number of international companies with considerable experience in collaborative approaches and new ways of working. The KRG could form partnerships with such companies and benefit from their experience in legislating and implementing new rules for the construction sector. Since construction practitioners in both private and public sectors are not familiar with collaborative approaches, significant effort needs to be expended in order to increase the level of awareness toward collaboration. At this stage, universities, research centres and government departments can have a crucial role. These organisations could help by organising introductory seminars and workshops about collaboration in the construction industry. These presentations could have a significant impact to increase awareness and to reduce resistance to change in construction practices (Arayici et al., 2011).

As little literature exists on collaboration in construction projects in Kurdistan region, further research is essential. The KRG needs to collaborate with a research institution in the region to investigate practical ways to implement collaboration in the construction sector. Construction industries faces similar problems in other developing countries. Therefore, the factors identified and suggested methods of implementation could be usefully applied in other countries.

\section{Conclusion}

Collaborative construction practices are still far from effective in developing countries in general, and in the Kurdistan region in particular. To develop a successful collaboration, a wide range of factors should be considered. Since many attributes and factors have been linked to improving collaboration in the construction industry, confusion exists in identifying the most critical factors required to deliver effective collaboration. This paper identified 11 factors as essential for achieving effective collaboration in the construction sector. These factors were divided into two groups: hard and soft factors. Soft factors consist of trust, communication, mutual goals, commitment and culture. The necessary hard factors include conflict resolution systems, top management support, gain-pain sharing, resource sharing, clear roles and the early involvement of key participants.

It is recommended that KRG demand new rules to be applied in public projects. New policies at the bid awarding stage to ensure that contracts are not awarded based only on the lowest initial bid. KRG also needs to encourage early involvement of contractors through imposing new regulations. Additionally, the study suggests that KRG could form partnerships with international construction companies that have experience in collaborative working and benefit from their experience in legislating and implementing new rules. Furthermore, the 
regional government needs to collaborate with a research institution in the region to investigate practical ways to implement collaboration in the construction sector.

\section{References}

Abramzon, S., Burger, N., Glick, P., Kumar, K., Montemayor, C. K., Mejia Gonzalez, N. J., . . . Setodji, C. M. (2016). Calculating the Gross Regional Product of the Kurdistan RegionIraq: Rand Corporation Santa Monica, CA.

Arayici, Y., Coates, P., Koskela, L., Kagioglou, M., Usher, C., \& O'reilly, K. (2011). Technology adoption in the BIM implementation for lean architectural practice. Automation in Construction, 20(2), 189-195.

Barnard, M. (2013). Not The Iraq You Know: But the Iraq that Could Be. Harvard International Review, 34(4), 32.

Bayramoglu, S. (2001). Partnering in construction: Improvement through integration and collaboration. Leadership and Management in Engineering, 1(3), 39-43.

Black, C., Akintoye, A., \& Fitzgerald, E. (2000). An analysis of success factors and benefits of partnering in construction. International Journal of Project Management, 18(6), 423-434.

Bresnen, M., \& Marshall, N. (2000a). Building partnerships: case studies of client-contractor collaboration in the UK construction industry. Construction Management \& Economics, 18(7), 819-832.

Bresnen, M., \& Marshall, N. (2000b). Motivation, commitment and the use of incentives in partnerships and alliances. Construction Management \& Economics, 18(5), 587-598.

Chan, A. P., Chan, D. W., Chiang, Y. H., Tang, B.-S., Chan, E. H., \& Ho, K. S. (2004). Exploring critical success factors for partnering in construction projects. Journal of construction engineering and management, 130(2), 188-198.

Chan, A. P., Chan, D. W., \& Ho, K. S. (2003). Partnering in construction: critical study of problems for implementation. Journal of Management in Engineering, 19(3), 126-135.

Cheng, E. W., \& Li, H. (2001). Development of a conceptual model of construction partnering. Engineering, Construction and Architectural Management, 8(4), 292-303.

Cheng, E. W., Li, H., \& Love, P. (2000). Establishment of critical success factors for construction partnering. Journal of Management in Engineering, 16(2), 84-92.

Dikmen, I., Birgonul, M. T., Ozorhon, B., \& Eren, K. (2008). Critical success factors for partnering in the Turkish construction industry. Paper presented at the Procs 24th Annual ARCOM Conference.

Elkhalifa, A. (2016). The magnitude of barriers facing the development of the construction and building materials industries in developing countries, with special reference to Sudan in Africa. Habitat International, 54, 189-198.

Giang, D. T., \& Pheng, L. S. (2011). Role of construction in economic development: Review of key concepts in the past 40 years. Habitat International, 35(1), 118-125.

Grilo, A., Zutshi, A., Jardim-Goncalves, R., \& Steiger-Garcao, A. (2013). Construction collaborative networks: the case study of a building information modelling-based office building project. International Journal of Computer Integrated Manufacturing, 26(1-2), 152-165.

Hughes, D., Williams, T., \& Ren, Z. (2012). Differing perspectives on collaboration in construction. Construction Innovation, 12(3), 355-368.

Koraltan, S. B., \& Dikbas, A. (2002). An assessment of the applicability of partnering in the Turkish construction sector. Construction Management \& Economics, 20(4), 315-321.

Koutsikouri, D., Austin, S., \& Dainty, A. (2008). Critical success factors in collaborative multidisciplinary design projects. Journal of Engineering, Design and Technology, 6(3), 198226. 
Kożuch, B., \& Sienkiewicz-Małyjurek, K. (2016). Factors of effective inter-organizational collaboration: a framework for public management. Transylvanian Review of Administrative Sciences, 12(47), 97-115.

Latham, S. M. (1994). Constructing the team.

Lopes, J., Ruddock, L., \& Ribeiro, F. L. (2002). Investment in construction and economic growth in developing countries. Building Research \& Information, 30(3), 152-159.

Lu, S., \& Yan, H. (2007). A model for evaluating the applicability of partnering in construction. International Journal of Project Management, 25(2), 164-170.

Meng, X. (2013). Change in UK construction: moving toward supply chain collaboration. Journal of Civil Engineering and Management, 19(3), 422-432.

Morrell, P. (2015). Collaboration for Change: The Edge Commission Report on the Future of Professionalism| Edge Debate: London: The Edge Commission, May.

Muhammed, T. A. (2015). DELAYS IN CONSTRUCTION.

Mustafa, F. A. (2017). Performance assessment of buildings via post-occupancy evaluation: A case study of the building of the architecture and software engineering departments in Salahaddin University-Erbil, Iraq. Frontiers of Architectural Research, 6(3), 412-429.

Nyström, J. (2005). The definition of partnering as a Wittgenstein family-resemblance concept. Construction Management and Economics, 23(5), 473-481.

Ofori, G. (2000). Challenges of construction industries in developing countries: Lessons from various countries. Paper presented at the 2nd International Conference on Construction in Developing Countries: Challenges Facing the Construction Industry in Developing Countries, Gaborone, November.

Ofori, G. (2007). Construction in Developing Countries. Construction Management and Economics, 25(1), 1-6. doi: 10.1080/01446190601114134

Patel, H., Pettitt, M., \& Wilson, J. R. (2012). Factors of collaborative working: a framework for a collaboration model. Appl Ergon, 43(1), 1-26. doi: 10.1016/j.apergo.2011.04.009

Rahman, S. H. A., Endut, I. R., Faisol, N., \& Paydar, S. (2014). The importance of collaboration in construction industry from contractors' perspectives. Procedia-Social and Behavioral Sciences, 129, 414-421.

RTI International. (2008). Kurdistan Region Economic Development Assessment.

Shawkat, L. W., Al-Din, S. S. M., \& Kuzović, D. (2018). Opportunities for Practicing Sustainable Building Construction in Kurdistan Region, Iraq. Journal of Contemporary Urban Affairs, 2(1), 96-101.

Shelbourn, M., Bouchlaghem, N., Anumba, C., \& Carrillo, P. (2007). Planning and implementation of effective collaboration in construction projects. Construction Innovation, 7(4), 357-377.

World Bank. (2015). THE KURDISTAN REGION OF IRAQ. Assessing the Economic and Social Impact of the Syrian Confl ict and ISIS.

Wu, S., Greenwood, D., \& Steel, G. (2008). Exploring the attributes of collaborative working in construction industry. Northumbria Working Paper Series: Interdisciplinary Studies in the Built and Virtual Environment, 1(2), 135-147.

Xue, X., Shen, Q., \& Ren, Z. (2010). Critical review of collaborative working in construction projects: business environment and human behaviors. Journal of Management in Engineering, 26(4), 196-208.

Yeung, J. F., Chan, A. P., \& Chan, D. W. (2007). The definition of alliancing in construction as a Wittgenstein family-resemblance concept. International Journal of Project Management, 25(3), 219-231.

Zebari, H. N., \& Ibrahim, R. K. (2016). Methods \& Strategies For Sustainable Architecture In Kurdistan Region, Iraq. Procedia Environmental Sciences, 34, 202-211. 